\title{
APRENDIZAJE SOCIAL EN BEBÉS DE CERO A TRES AÑOS: INCLUIR LA NOCIÓN DE APRENDIZAJE EN UNA GUARDERÍA EN LA BRETAÑA, FRANCIA
}

\author{
SOCIAL LEARNING IN 0 TO 3 YEAR OLD BABIES: \\ INCLUDING THE NOTION OF LEARNING \\ IN A NURSERY IN BRITTANY, FRANCE
}

Jimena Tirado Torres ${ }^{1}$

Recibido: febrero 10, 2021 - Aceptado: marzo 12, 2021

\section{RESUMEN}

La etapa de la primera infancia es el período del ser humano que va del nacimiento a los ocho años; constituye un momento único del crecimiento en que el cerebro se desarrolla notablemente. La autora presenta hallazgos sobre la desconfianza que existe en las guarderías, en Francia, respecto a la noción de aprendizaje en la etapa de los cero a los tres años y señala como contraparte evidencias científicas que incluyen a Andrew N. Meltzoff, Anne-Sophie Rochegude y Louise Michaud, así como pautas por parte de la UNESCO, la OCDE, leyes y decretos particulares franceses que sustentan la pertinencia del aprendizaje en esa etapa. Se sustenta que el aprendizaje social o vicario es a través del cual los bebés aprenden, simplemente observando la conducta de un modelo social. La imitación demuestra probablemente uno de los efectos más largos en el aprendizaje y el comportamiento en la primera infancia.

\footnotetext{
Maestría en Dirección de Capital Humano, Universidad Panamericana, México. Máster en Calidad y Mejora de la Educación, Universidad Autónoma de Madrid, España. Especialidad en Dirección de la Persona Humana en la Organización y Licenciada en Pedagogía, Universidad Panamericana. Profesora certificada de español por el Colegio de Español Tía Tula de Salamanca. Actualmente está en vías de obtener el Certificado de Aptitud Profesional de Acompañamiento Educativo de la Primera Infancia (Certificat d'Aptitude Professionnelle Accompagnement Éducatif Petite Enfance), por el gobierno de Francia a través del Rectorado de Grenoble, departamento de Haute-Savoie, Francia. Actualmente es agente de animación de la primera infancia en inglés, Guardería «Le P’tit Club» de L'association l'Eveil du Rohig, Saint-Nolff, Francia. jimena.tirado01@gmail.com
} 
Por último, la autora realiza propuestas para incluir la noción de aprendizaje en el proyecto educativo y proyecto pedagógico en una guardería al norte de Francia, sin que resulte ambicioso o sea limitante en la libre exploración de los pequeños.

Palabras clave: aprendizaje social, aprendizaje vicario, aprendizaje observacional, imitación, modelos, guarderías, primera infancia, Francia.

\begin{abstract}
Early childhood is the period from birth to eight years of age and is a unique time of growth when the human brain develops significantly. The author presents findings on the mistrust of the notion of learning at the 0-3 years stage in French nurseries and countervailing scientific evidence including Andrew N. Meltzoff, Anne-Sophie Rochegude and Louise Michaud, as well as guidelines from UNESCO, the OECD, laws and decrees particular to France that support the relevance of learning at this stage. It is argued that social or vicarious learning is whereby infants learn simply by observing the behaviour of a social model. Imitation probably demonstrates one of the most long-lasting effects on learning and behaviour in early childhood. Finally, the author makes proposals to include the notion of learning in the educational project and pedagogical project in a nursery in France, without being ambitious or limiting the free exploration of the little ones.
\end{abstract}

Keywords: Social Learning, Vicar Learning, Observational Learning, Imitation, Models, Nursery, Early childhood, France.

\title{
INTRODUCCIÓN
}

El problema de estudio es la desconfianza en Francia para usar el término «aprendizaje» en los entornos de la primera infancia -en bebés de cero a tres años-, esto es debido a que se vincula con el aprendizaje que adquirirán en el colegio a partir de los tres años y se teme una sobreestimulación en los pequeños. Es común que en las guarderías se hable de acoger o cuidar a los bebés y, en algunas, se mencione un proceso educativo, pero no de aprendizaje.

Con el propósito de contrarrestar lo anterior, se presenta el sustento pedagógico sobre la pertinencia de hablar de un aprendizaje social en esta etapa. Los hallazgos sobre la desconfianza en la noción del aprendizaje parten desde lo teórico, así como de una experiencia profesional en una guardería privada bilingüe, ubicada en el norte de Francia.

Este tema merece ser estudiado porque, a pesar de la cautela al usar el término aprendizaje, los bebés sí aprenden y mi propósito es presentar las formas en que aprenden de cero a tres años. Ellos aprenden imitando, observando a los otros en un entorno social, lo cual tiene implicaciones pedagógicas que necesitan ser analizadas para involucrar a los profesionales de la primera infancia, enfermeras y puericultoras.

El problema planteado es importante y ya se ha abordado en la misma sociedad francesa, por lo que vale la pena que se estudie por pedagogos, psicólogos y neurocientíficos, para 
evitar el temor a incluir la noción de aprendizaje en la primera infancia. El presente estudio pretende sumarse a las teorías y pautas internacionales que apoyan el aprendizaje en los pequeños con un sustento teórico que devela la capacidad para aprender de los bebés. desde un aprendizaje observacional o social.

Los pequeños van aprendiendo continuamente y creando los cimientos para un posterior aprendizaje cognitivo que adquirirán en la escuela. Sin embargo, mientras esta etapa llega, son las guarderías el lugar donde también se desarrolla el aprendizaje en los bebés. Partiendo de estas afirmaciones, se ofrecen propuestas prácticas para incluir el término aprendizaje en el proyecto educativo y pedagógico de una guardería en Francia.

\section{FUNDAMENTO PEDAGÓGICO SOBRE EL APRENDIZAJE EN LA PRIMERA INFANCIA}

\section{Primera infancia}

Uno de los ámbitos pedagógicos es la etapa de la primera infancia o también llamada educación inicial. La Organización de las Naciones Unidas para la Educación, la Ciencia y la Cultura enfatiza la importancia de esta etapa, creando un concepto con las siglas AEPI: atención y educación de la primera infancia.

Se define a la primera infancia como:

El período de la vida de un ser humano que va del nacimiento a los ocho años y constituye un momento único del crecimiento en que el cerebro del ser humano se desarrolla notablemente. Durante esta etapa, los niños reciben una mayor influencia de sus entornos y contextos (UNESCO, 2020).

El pedagogo tiene cabida en la etapa de la primera infancia construyendo teorías sobre los procesos de enseñanza-aprendizaje que ocurren en los pequeños, elaborando metodologías para aplicar teorías y procedimientos de actividades que contribuyan al desarrollo de los bebés y niños, diseñando recursos didácticos que promuevan el aprendizaje y desarrollo integral, creando y acomodando los espacios para un mejor despertar en los bebés, entre otras tareas. El pedagogo es un profesional ideal para formar parte de un equipo multidisciplinario en el descubrimiento de nuevos hallazgos sobre la primera infancia.

Es cierto que los psicólogos son quienes han despuntado en la creación de teorías y estudios que develan el desarrollo intelectual, motriz, socioemocional y afectivo de los infantes en este período. Sin embargo, este es un campo amplio para que los pedagogos se sumen a los descubrimientos para un mejor entendimiento del ser humano. Al final, en toda institución o lugar que exista una persona, habrá campo de acción para un pedagogo.

La primera infancia es la etapa inicial en el ciclo de la vida. El inicio de la vida no es ni más ni menos importante que el resto de las etapas, pero sí requiere de una especial y cuidadosa atención a los recién nacidos y bebés. Los adultos nos convertimos en educadores (emisores) y disponemos de artículos para que los bebés descubran y aprendan, pero en un primer momento no siempre habrá respuestas del bebé (receptor). Por esa razón, es una etapa vital donde se requiere sembrar y regar diariamente la mente, el cuerpo y alma de los bebés. Con 
sembrar y regar me refiero a mostrar el mundo, ayudarles a descubrir de manera segura lo que hay fuera de ellos, hablar con la voz y con la mirada, abrazarlos con afecto, disponer espacios seguros para su desarrollo motor, atender sus necesidades físicas, enseñarles buenos hábitos, enseñarles a no mentir, valores, a ser buenos con los demás, a ser resilientes, etcétera.

Siendo la educación objeto de estudio del pedagogo, podemos señalar que la educación es todo proceso humano en el cual interactúan al menos dos personas: la que transmite o enseña, y la que adquiere o aprende aquello mostrado, y debe tener una intención u objetivo en busca del perfeccionamiento del receptor.

En la primera infancia, la persona que adquiere o aprende la información es el recién nacido, bebé o niño, y la persona que transmite o enseña son los padres, los abuelos, la niñera y/o el personal de una guardería.

Los bebés son personas en vías de desarrollo y algunos requieren ser cuidados en una guardería; es decir, necesitan de un refugio temporal en ausencia de sus padres o tutores, donde se sientan seguros física y emocionalmente, donde sean asistidos en sus necesidades fisiológicas, donde se les ayude en su desarrollo personal y social, y alentarlos y auxiliarlos en su desarrollo cognitivo... Este encuentro, en el sentido más noble de la palabra, es siempre educativo. Señala Anne-Sophie Rochegude: «Saber acoger al bebé, en todos los sentidos de la palabra, es participar plenamente en su educación» (B. Cyrulnik et al., p. 501).

\section{Aprendizaje y aprendizaje social}

Definiciones de aprendizaje podemos encontrar muchas, pero para este artículo académico, tomé en consideración que el aprendizaje «es el proceso mediante el cual un sujeto adquiere destrezas o habilidades prácticas, incorpora contenidos informativos, o adopta nuevas estrategias de conocimiento y/o acción» (Diccionario de las Ciencias de la Educación, 2003).

En el caso de los bebés, ellos aprenden desde recién nacidos y van almacenando datos e información en su memoria, la cual poco a poco se desarrolla hasta alcanzar la adquisición de capacidades. Para ellos, el aprendizaje parte de la interacción con otras personas, el ambiente y otros objetos. Su primera forma de aprendizaje es social u observacional.

\footnotetext{
Aprendizaje social es un conjunto de aprendizajes que hacen referencia a conductas específicas y directamente ligadas a la vida social, como hábitos sociales, actitudes, valores, etcétera. Bandura sostiene que la mayor parte de la conducta social se desarrolla a través del aprendizaje por observación de modelos y que se ejecuta en función de las contingencias del refuerzo ambiental (Diccionario de las Ciencias de la Educación, 2003.)
}

Posteriormente a los hallazgos encontrados por el suizo Jean W. Fritz Piaget, referentes al desarrollo humano, Bandura (1961) realizó estudios del aprendizaje observacional, haciendo una «declaración considerada, entonces radical: los niños pueden aprender simplemente observando la conducta de un modelo social, incluso sin que antes hubieran realizado esas mismas respuestas o sin recibir ningún reforzamiento por llevarlos a cabo» (D. R. Shaffer, 2002, p. 50).

Es decir, que a pesar de que no exista una intencionalidad del adulto por enseñar algo a los bebés, ellos están aprendiendo solamente con el acto de observar. Esta acción es también llamada «aprendizaje vicario, aprendizaje social, aprendizaje por modelos o aprendizaje imitativo. Aprendizaje que se obtiene por la observación de la conducta, consecuencias, procesos, 
etcétera, de un modelo. Se fundamenta en los procesos imitativos complejos, integra dimensiones cognitivas y afectivas» (Diccionario de las Ciencias de la Educación, 2003).

El reconocido psicólogo estadounidense Andrew N. Meltzoff ha realizado descubrimientos revolucionarios sobre la imitación de los bebés, que modificaron la comprensión del aprendizaje social durante los primeros años de vida y afirma que «la imitación es el mecanismo capital del aprendizaje para el bebé en la edad preverbal» (B. Cyrulnik et al., 2019, p. 111).

Meltzoff en su artículo $A u$ commencement était l'imitation [«Al principio era la imitación»] hace referencia a su modelo AIM (Active Intermodal Mapping) o mapeo intermodal, el cual se refiere a que «los niños pequeños utilizaban el gesto del adulto como una meta a la que intentaban corresponder voluntariamente, utilizando la información de sus propios movimientos corporales» (B. Cyrulnik et al., 2019, p. 115).

Este hallazgo provocó un cambio en la teoría de Piaget referente al período sensorio-motor declarando que:

Los bebés son capaces, desde su nacimiento, de actuar sobre la base de representaciones almacenadas, mucho antes del subestadio 4 de Piaget (de ocho a 12 meses); los niños pequeños reconocen las correspondencias entre ellos mismos y los demás. A una edad muy temprana, están mucho más adaptados socialmente de lo que admiten las teorías psicológicas tradicionales (B. Cyrulnik et al., 2019, p. 115).

Lo anterior revolucionó los estudios que Piaget había elaborado. Actualmente se reconoce que los bebés tienen un desarrollo más avanzado de lo que se creía a través de la observación y la imitación. Además, Meltzoff también afirma que:

Los bebés no sólo hacen gestos faciales. Hemos investigado la imitación vocal, que es un paso crucial en la adquisición del lenguaje. Hemos podido establecer rigurosamente que los niños de 12 a 20 semanas pueden imitar sonidos vocales. Los bebés franceses empiezan a balbucear en francés y los estadounidenses en inglés. Los bebés perfeccionan y agudizan sus primeras producciones lingüísticas escuchando e imitando a personas de su cultura (B. Cyrulnik et al., 2019, p. 115).

Es evidente que los bebés están más adaptados para convivir y aprender de lo que pensábamos. Los bebés aprenden mediante observación e imitación de sus pares y de los adultos a su cargo, por lo cual en todo momento se debe prestar atención en el comportamiento y desenvolvimiento de los profesionales en presencia de los bebés. Ellos están educando con su ejemplo, aunque no sean conscientes de que los bebés están absorbiendo todo lo que sucede a su alrededor y, por ende, están aprendiendo.

«La imitación demuestra probablemente uno de los efectos más largos en el aprendizaje y el comportamiento en la primera infancia» (Jones y Herbert, 2006). Es decir que el actuar de los bebés será influenciado por lo que observen de las personas que los acompañen en su desarrollo.

En línea con el aprendizaje social, Meltzoff afirma:

Mi teoría es que no nacemos aislados socialmente. Estamos desde el principio conectados a los demás, a esos otros percibidos «como yo». Esto permite el rápido aprendizaje por observación: puedo aprender sobre mí mismo y mis capacidades observando las consecuencias de sus acciones y puedo imprimirles el significado que siento en mi propia experiencia. La comprensión social se basa en la similitud del otro (el como yo) que, aunque sea diferente de uno mismo, nos parece lo suficiente como para convertirse en nuestro modelo y nosotros en su intérprete (B. Cyrulnik et al., 2019, p. 122). 
Los hallazgos anteriores me conducen a aseverar que los trabajadores de las guarderías no solamente son encargados de acoger o cuidar a los bebés, sino que también son modelos para los pequeños, son referentes porque los observan y los pueden imitar. Pero también, los mismos bebés que observan e imitan, a la vez, ¡también son modelos de otros bebés con los que conviven! Y sin ser menos importante, también lo son los padres de familia que interactúan con el personal de la guardería y sus bebés.

Entonces, en las guarderías podemos encontrar varios posibles modelos a seguir. Estos modelos -consciente o inconscientemente- se convierten en transmisores de información ya que guían, forman, ejemplifican, animan, conducen, instruyen, cultivan, es decir: enseñan. Estos modelos se vuelven parte activa del proceso de enseñanza-aprendizaje de los bebés. Al imitar a un modelo, los bebés muestran su capacidad para aprender o reproducir conductas.

El trabajo de los profesionales no solo repercute en el presente, sino también en el futuro a corto y largo plazo. El rol del personal tiene y tendrá una trascendencia muy importante en las vidas de los pequeños y, por ende, en la de sus padres.

\section{HALLAZGOS SOBRE LA DESCONFIANZA REFERENTE} A LA NOCIÓN DE APRENDIZAJE DURANTE

\section{LA PRIMERA INFANCIA EN LAS GUARDERÍAS DE FRANCIA}

Con lo sustentado hasta el momento, podría ser natural hablar aprendizajes en la primera infancia, pero no necesariamente lo es en todas las culturas. Durante mi experiencia profesional en una guardería en Francia, me di cuenta del temor o la precaución que tienen al emplear el término aprendizaje: no les resulta conveniente y, por el contrario, el término usado es educación. Continué investigando y efectivamente es una tendencia generalizada en ese país. Cabe señalar que la finalidad de las guarderías en Francia es acoger o recibir (emplean el término «accueillir», en francés).

Como parte de los hallazgos, en primer lugar, expongo mi experiencia trabajando en una guardería al norte de Francia y, en segundo lugar, extractos de investigaciones realizadas por Sylvie Rayna, experta en temas educativos en Francia, quien comenta sobre el malestar respecto a la noción de aprendizaje en las guarderías.

\section{Hallazgo 1: experiencia profesional}

Como primer hallazgo, deseo incluir mi experiencia trabajando como «agente de animación en inglés» en Le P'tit Club, conformada por L'association l'Eveil du Rohig, una guardería privada, bilingüe (francés-inglés) en la Bretaña. Esta guardería proporciona servicio a 35 bebés a partir de diez semanas de nacidos hasta los tres años -mayoritariamente para hijos de trabajadores de compañías internacionales- y también otorga tres becas para bebés de personas que viven en la comunidad de extranjeros Emmaüs. Ofrece un horario de atención de $07 \mathrm{~h} 30$ a $19 \mathrm{~h} 00$ de lunes a viernes.

Esta guardería abrió sus puertas en abril de 2019. Fue la tercera sucursal del grupo. Alrededor del 30\% de los profesionales son de habla inglesa y el resto son franceses. Trabajé con un grupo de bebés de diez semanas hasta 18 meses, a la par de mis estudios para certificarme como profesional de acompañamiento educativo de la primera infancia. 
La misión de P’tit Club es:

\begin{abstract}
Acoger a los niños pequeños en un entorno seguro y favorable a su desarrollo, permitiendo así a sus padres ejercer o no una actividad profesional. Conciliar las necesidades del niño, los padres y la empresa, respetando la individualidad de cada uno. En cuanto a su proyecto asociativo está basado en tres pilares: 1. sociocracia: un modo de gobierno que tiene en cuenta la inteligencia colectiva a través de la participación y el empoderamiento de todos en la toma de decisiones diaria; 2. bilingüismo inglés-francés, y 3. multiculturalismo (Le P'tit Club, 2020).
\end{abstract}

Como parte fundamental de su proyecto pedagógico se estipula: acoger a los niños en el respeto de su individualidad: las actividades propuestas -y nunca impuestas- favorecen el despertar y el desarrollo de cada uno según sus necesidades y deseos. Todas las semanas se organizan talleres que integran la naturaleza y, al menos una vez al trimestre, se invita a los padres a compartir el almuerzo o un refrigerio por la tarde con su hijo y los profesionales de la guardería.

La Directora General, comenta para esta investigación: «No hablamos de aprendizaje en la guardería, pero sí de educación en las normas de la vida en comunidad, como la higiene, el lavado de manos, la educación, el respeto, etcétera. El aprendizaje lo adquieren en la escuela, el color, la lectura, etcétera» (C. Le Garrec, comunicación personal, 21 de septiembre de 2020).

\title{
Hallazgo 2: investigaciones de Sylvie Rayna
}

Rayna en su artículo Regard sur les apprentissages des tout-petits. Comment les enfants apprennent-ils [«Una mirada al aprendizaje de los niños pequeños. ¿Cómo aprenden los niños?»], comenta:

La noción de aprendizaje en los niños pequeños está muy presente en el lenguaje cotidiano, así como en los libros de puericultura, y se refiere a una amplia gama de adquisiciones (aprender a caminar, a hablar, etcétera). Al mismo tiempo, en Francia, el término goza de una gran desconfianza en los entornos de la primera infancia (de cero a tres años) porque se vincula con el término aprendizaje en la escuela, hace referencia al aprendizaje temprano y a la sobreestimulación.

Aunque el término aprendizaje está omnipresente en el plan de estudios de la escuela infantil, no aparece en los textos oficiales relativos a los servicios para la primera infancia. Sin embargo, a partir del decreto del 1 de agosto de 2000, se declaró la función educativa de estos servicios. Como ya no son simples guarderías, ahora se les exige un proyecto educativo para la acogida, el cuidado, el desarrollo, la estimulación y el bienestar de los niños (distinguiéndolas claramente del mundo escolar), pero no se especifica nada realmente en cuanto a los contenidos.

Aunque es comúnmente aceptado que el juego es la actividad fundamental de los niños pequeños y que aprenden jugando, la presencia de profesionales del juego es minoritaria en Francia.

Hay pocos educadores de la primera infancia en las guarderías y se presta muy poca atención a la dimensión educativa en la formación de los principales ejecutores del trabajo con los niños pequeños: los asistentes de guardería y los auxiliares de guardería. En nuestro país, la cultura profesional de los servicios de atención a la infancia está más teñida, por su historia pasada y presente, de un discurso médico y psicológico, lo que explica, en parte, las dificultades que encuentran un buen número de responsables de estos servicios (principalmente enfermeras de guardería) y sus equipos (predominantemente paramédicos) para elaborar el proyecto educativo 
que se requiere actualmente. Hay que señalar que, en la actualidad, el propio término «cuidador», que ciertamente tiene el mérito de agrupar las distintas categorías de personal de la primera infancia y hacer visible su función relacional, no se refiere al aspecto educativo, más bien se refiere al cuidado de los niños pequeños.

Además del intercambio imitativo, hemos observado formas de cooperación entre los niños que también enriquecen lo que aprenden durante sus actividades lúdicas. Así, su necesidad de comunicación puede satisfacerse no sólo en la relación con el adulto, sino también con otros niños, a través de la mediación del juego en el que construyen juntos sus conocimientos (S. Rayna, 2003).

Aunque el artículo haya sido escrito en 2003, S. Rayna expresa perfectamente lo que sucede en la actualidad. En paralelo, además, explica la dificultad de los directores para elaborar el proyecto educativo y pedagógico que se requiere. En mi experiencia profesional, en los años 2019 y 2020, confirmé la desconfianza a la que ella se refiere en su artículo.

\section{PERTINENCIA DEL APRENDIZAJE EN}

\section{LA PRIMERA INFANCIA, EN LAS GUARDERÍAS}

Presento evidencias de dos reconocidos investigadores franceses del Instituto de la Primera Infancia Boris Cyrulnik: Anne-Sophie Rochegude (directora científica) y Louise Michaud (director del Departamento de Arquitectura y Planificación del Espacio). En sintonía con las teorías revisadas de A. Meltzoff, Anne-Sophie Rochegude afirma que:

Acoger no es sólo un servicio, sino un producto propuesto y es ante todo una interacción. Acoger a un bebé a diario, como profesional, es también dar cobijo. Libre exploración educativa: porque el niño que explora con confianza el mundo a través de las mil y una puertas que le abrimos, es un bebé que aprende, que crece, que florece... Y saber acogerlo, en todo el sentido de la palabra, es participar plenamente en su educación (B. Cyrulnik et al., 2019, p. 501).

Los profesionales de la primera infancia o cuidadores, crean lazos fuertes con los bebés y es evidente que de esa relación tan íntima surja un proceso educativo permanente. Rochegude propone la educación en la primera infancia desde «cinco pilares de la libre exploración educativa que son: exploración, placer, confianza, apego, aprendizaje y libertad» (B. Cyrulnik et al., 2019, p. 500).

Rocheguede está convencida del empleo del término aprendizaje y además, ¡lo sugiere como uno de los pilares de la educación en la primera infancia! Asimismo, para que la exploración de los bebés sea placentera y confiada, es imprescindible el buen acomodo de los espacios en una guardería y la ubicación de los rincones lúdicos, para que aprendan dentro de un ambiente seguro.

En palabras de Louise Michaud:

Al ofrecerle al niño un espacio rico en experimentación sensorial-motora, ayudamos a encender el fuego de su curiosidad, tan preciada, y le permitimos un anclaje más profundo de su aprendizaje. Siendo el niño por naturaleza un aventurero del descubrimiento y un investigador empedernido, debemos ofrecerle un campo de exploración que satisfaga sus deseos. Todo espacio es aprendizaje y en todo aprendizaje debe haber gozo (B. Cyrulnik et al., 2019, p. 522). 
Mientras el personal de la guardería cuida a los pequeños, en ausencia de sus padres, ellos son los encargados de su desarrollo y de acomodar los recursos que se tienen para su mayor beneficio. «Evidentemente, jsomos responsables del espacio físico que se ofrece a los pequeños! Pero, por otro lado, es el bebé quien podrá maximizar las oportunidades de aprendizaje por sí mismo» (B. Cyrlunik et al., 2019, p. 502).

Comparto el pensamiento de A. Meltzoff, A.S. Rochegude y L. Michaud, y no es atrevido ni escrupuloso afirmar que los bebés muestran capacidad para aprender desde que llegan a este mundo. Ellos aprenden continuamente y van creando los cimientos para un posterior aprendizaje cognitivo. Por lo anterior, considero que es competencia de las guarderías el desarrollo del aprendizaje en los bebés.

\title{
PAUTAS INTERNACIONALES Y SUSTENTO JURÍDICO FRANCÉS SOBRE EL APRENDIZAJE EN LA PRIMERA INFANCIA
}

\section{Organización de las Naciones Unidas para la Educación, la Ciencia y la Cultura (UNESCO)}

A nivel internacional, la UNESCO realiza recomendaciones a los países para asegurar la educación inclusiva y que brinden aprendizajes a lo largo de la vida a sus ciudadanos. La UNESCO ha apostado por el enfoque a la atención y educación de la primera infancia (AEPI), siendo reforzado con la Agenda de educación 2030, sustentada en la Declaración de Incheon, y en su Marco de acción, el cual pretende incidir en las políticas de los países hacia una educación inclusiva, equitativa, de calidad y un aprendizaje a lo largo de la vida para todos. En específico en esta Declaración el objetivo 4 es:

\begin{abstract}
Garantizar una educación inclusiva y equitativa de calidad, y promover oportunidades de aprendizaje permanente para todos; y la meta 4.2., indica el asegurar que todas las niñas y todos los niños tengan acceso a servicios de atención y desarrollo en la primera infancia y educación preescolar de calidad, a fin de que estén preparados para la enseñanza primaria (UNESCO, 2016).
\end{abstract}

La UNESCO ha apostado por hablar del aprendizaje y esto también lo encontramos en el informe Cuidado y desarrollo de la primera infancia. El desarrollo del niño en la primera infancia: echar los cimientos del aprendizaje:

\footnotetext{
A cada edad del niño pequeño, corresponde una modalidad de aprendizaje, ya sea el aprendizaje basado en la indagación y la experimentación de carácter físico, verbal y afectivo, entre el primer y el tercer año de vida, ya sean los primeros ejercicios preescriturales a partir de los tres años, ya se trate de la solución de problemas sencillos de que es capaz el niño entre los tres y los seis años (UNESCO, 1999).
}

\section{Organización para la Cooperación y el Desarrollo Económicos (OCDE)}

Otro organismo que marca pautas en materia educativa es la OCDE. Apostar por un adecuado desarrollo de los bebés y niños que están en la etapa de la primera infancia es uno de los temas que se debate y se cuestiona, ya que cada vez hay más evidencias de los grandes 
beneficios personales y sociales que existen cuando los bebés tienen acceso a la educación y atención a temprana edad.

Según un informe de la OCDE, «es recomendable que los países redoblen esfuerzos para ofrecer educación y atención de la primera infancia (EAPI) asequibles y de alta calidad, y así brindar a todos los niños la oportunidad de alcanzar su potencial y mejorar la movilidad social» (OCDE, 2017).

Además, en la publicación Starting Strong (2017), existen indicadores clave de la OCDE sobre educación y atención a la primera infancia: se «muestra que en años recientes la mayoría de los gobiernos han aumentado sus inversiones para ampliar la matrícula y abrir más guarderías y escuelas».

\section{Francia}

Particularmente en Francia, país donde se recabó la información para este trabajo, la etapa de la primera infancia va de los cero a los seis años. Las guarderías brindan atención a bebés de diez semanas de nacidos hasta los tres años, es decir hasta antes de entrar a la escuela maternal.

El Sistema Educativo Francés se reformó en 2019, incrementando los años obligatorios de estudio. El Ministro de Educación, Jean-Michel Blanquer, impulsó una reforma educativa con el apoyo del presidente Emmanuel Macron, en la que se promulgó la Ley número 2019-79 del 26 de julio de 2019, «Por una escuela de confianza» (Loi $\left.n^{\circ} 2019-791,2019\right)$, apareciendo en el boletín oficial del 28 de julio de 2019 con la llamada «Escuela de la confianza». La reforma Blanquer señala que la educación será obligatoria de los tres hasta los 18 años, a partir del ciclo escolar 2019/2020. Anteriormente, la educación era obligatoria de los seis a los 16 años.

En la figura 1 se aprecia en forma esquemática, la estructura de la educación en Francia. La línea roja horizontal parte de tres a los 18, indicando los años de educación obligatoria a tiempo completo. En algunas escuelas maternales admiten a los pequeños antes de los tres años para que se vayan familiarizando, pero no es obligatorio.

\section{Figura 1. Esquema de la estructura de la educación en Francia}

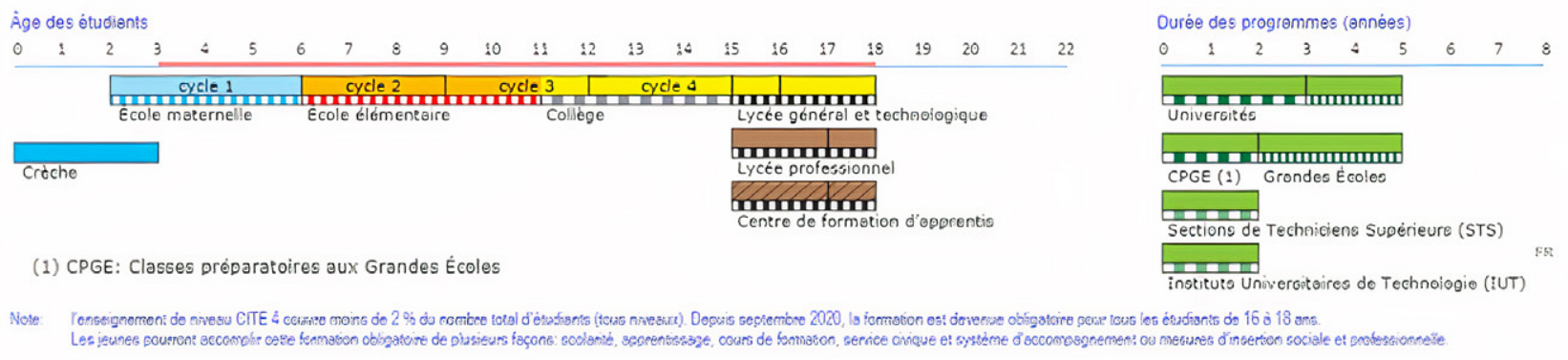

Nota: Tomado de The structure of the European Education Systems 2020/21 (p. 20), por European Commission/ EACEA/Eurydice, 2020, Schematic Diagrams, Eurydice-Facts and Figures. Luxemburg: Publications Office of the European Union. 
Los bebés de cero a tres años no entran dentro del esquema obligatorio de educación; sin embargo, el gobierno, a través del Ministerio de Solidaridad y de la Salud, regula las guarderías, los centros de acogida para los bebés y a los profesionales de la primera infancia autorizados para recibir en sus casas a los bebés. Además, protege y promueve los derechos de los niños a través de la «Convención Internacional sobre los Derechos del Niño» que firmó y ratificó en 1990, así como los dos «Protocolos facultativos» de 2000, sobre la participación de los niños en los conflictos armados y sobre la venta de niños, la prostitución infantil y la utilización de niños en la pornografía (Ministère de l'Europe et des affaires étrangères, 2017). Y más recientemente con la Carta nacional para la acogida de los bebés (2020) ["Charte nationale pour l'accueil du jeune enfant»], emitida por el Ministerio de Solidaridad y de la Salud, el 24 de enero de 2020.

La Carta establece diez principios escritos en primera persona -en la que se reflejan las necesidades de los bebés-, con el fin de garantizar las mejores condiciones de acogida para los pequeños. Reformula las prácticas profesionales para satisfacerlas, desde la perspectiva del interés superior del niño, y hace explícito el modo en que la primera infancia puede sentar las bases necesarias para un desarrollo saludable del niño -completo y armonioso-, respetuoso de los derechos, necesidades y singularidad de cada niño.

Desde mi punto de vista, este documento es poderosísimo y establece un referente para los cuerpos directivos de las guarderías o los jardines de niños, y para los profesionales de la primera infancia, en relación con las familias de los bebés. Sugiere replantear el quehacer de todos los actores de las guarderías que participan en el cuidado y la educación de los bebés; invita a la reflexión y a no perder de vista la finalidad última de los bebés: ellos necesitan crecer y desarrollarse en todas las esferas, con confianza, para promover su desarrollo afectivo y con ello el fortalecimiento de su autoestima.

Este documento está escrito magnánimamente desde la óptica de un bebé y tiene por finalidad acortar la distancia que, por lo general existe entre el bebé y el adulto para un mayor entendimiento del bebé.

\footnotetext{
Carta Nacional para la acogida de los bebés. Diez principios clave para crecer con confianza Necesito que me acojan independientemente de mi situación o la de mi familia, para crecer con serenidad.

1. Me muevo a mi propio ritmo y desarrollo todas mis facultades al mismo tiempo: para mí, todo es lenguaje, cuerpo, juego, experiencia. Necesito alguien que me hable, tiempo y espacio para jugar libremente y ejercer mis múltiples habilidades.

2. Soy sensible a mi entorno inmediato y al mundo que se me ofrece. Me siento bienvenido cuando mi familia es bienvenida, porque mis padres son mi punto de origen y mi puerto de anclaje. 3. Necesito profesionales que amablemente alienten mi deseo de aprender, socializar y descubrir, para sentirme bien y seguro.

4. Desarrollo mi creatividad y despierto mis sentidos a través de experiencias artísticas y culturales. Me abro al mundo a través de la riqueza de los intercambios interculturales.

5. El contacto real con la naturaleza es esencial para mi desarrollo.

6. Sea niña o niño, necesito ser valorada o valorado por mis cualidades personales, fuera de cualquier estereotipo, al igual que con los profesionales que me acompañan, ya que es gracias a estas mujeres y hombres que construyo mi identidad.

7. Necesito evolucionar en un ambiente lindo y saludable que sea propicio para mi despertar.

8. Para que me traten bien, es necesario que los adultos que me rodean sean bien tratados. El trabajo con niños pequeños requiere tiempo para reflexionar, documentar e intercambiar ideas con colegas y otros profesionales.
} 
9. Necesito que las personas que me cuidan estén bien formadas, y se interesen por los detalles de mi corta edad y mi situación de niño, que les han confiado mis padres.

Hasta el momento hemos revisado hallazgos que hablan sobre la desconfianza en la noción de aprendizaje, así como evidencias teóricas, recomendaciones internacionales, leyes y decretos franceses que sustentan la pertinencia del aprendizaje en la primera infancia. Por lo anterior, propongo algunas formas de incluir la noción de aprendizaje en el proyecto educativo y proyecto pedagógico de las guarderías, sin que resulte ambicioso o sea una limitante en la libre exploración de los pequeños.

\section{PROPUESTAS DE INCLUSIÓN DE LA NOCIÓN DE APRENDIZAJE EN EL PROYECTO EDUCATIVO Y PROYECTO PEDAGÓGICO DE LAS GUARDERÍAS}

El proyecto educativo de cada guardería es único y elaborado con base en su propia filosofía. Sin embargo, todas las guarderías suscriben un fin común: acoger, cuidar y velar por el desarrollo de los bebés/niños. Mi intención es complementar lo que en realidad sucede en los espacios de las guarderías y es que también los bebés aprenden en las guarderías. Para dar vida al proyecto educativo y concretar el cómo se desarrollará el aprendizaje de los bebés en el proyecto pedagógico, se propone desarrollar cada área y sus dimensiones en cada etapa del bebé.

Las ideas que a continuación expongo pueden incluirse en otras guarderías de Francia y /o en otras guarderías del mundo.

\section{Actividades guiadas}

La tabla 1 es una propuesta de formato $y$, a modo de ejemplo, incluyo dos actividades para dos etapas diferentes. En la tabla deberá incluirse:

- Etapas del bebé: de diez semanas a cuatro meses; de cuatro a ocho meses; de ocho a 12 meses; de 12 a 16 meses; de 16 a 20 meses; de 20 a 24 meses; de 24 a 28 meses; de 28 a 32 meses y de 32 a 36 meses.

- Áreas: sensorial, emocional, social, intelectual y física.

- Dimensiones: lenguaje expresivo; lenguaje comprensivo; habilidades motrices finas; habilidades motrices gruesas; percepción auditiva; percepción visual; percepción táctil; percepción olfativa y gustativa; esquema corporal; pensamiento lógico matemático; formación de hábitos, valores y desarrollo de autoestima.

- Actividad guiada: juegos o actividades que los profesionales propongan a los bebés/niños.

- Rincones lúdicos: se refiere a los espacios -abiertos o cerrados- para realizar las actividades propuestas. 
Tabla 1. Organización de actividades guiadas

\begin{tabular}{|l|l|l|l|l|}
\hline $\begin{array}{c}\text { Etapa del } \\
\text { bebé }\end{array}$ & \multicolumn{1}{|c|}{$\begin{array}{c}\text { Área de } \\
\text { desarrollo }\end{array}$} & \multicolumn{1}{|c|}{ Dimensiones } & Actividad guiada & \multicolumn{1}{|c|}{ Rincones lúdicos } \\
\hline $\begin{array}{l}10 \text { semanas } \\
\text { a } 4 \text { meses. }\end{array}$ & Sensorial. & $\begin{array}{l}\text { Percepción } \\
\text { visual. }\end{array}$ & $\begin{array}{l}\text { Mostrarle un } \\
\text { móvil con figuras } \\
\text { geométricas simples } \\
\text { en color blanco y } \\
\text { negro. }\end{array}$ & $\begin{array}{l}\text { Disponer al bebé en } \\
\text { el piso, en un tapete y } \\
\text { acompañarlo en sus } \\
\text { observaciones; dejarlo } \\
\text { explorar y ver su entorno. }\end{array}$ \\
\hline $\begin{array}{l}24 \text { a } 28 \\
\text { meses. }\end{array}$ & $\begin{array}{l}\text { Sensorial } \\
\text { social. }\end{array}$ & $\begin{array}{l}\text { Formación de } \\
\text { hábitos. } \\
\text { Valor del respeto. } \\
\text { Habilidades } \\
\text { motrices finas. }\end{array}$ & $\begin{array}{l}\text { Cuidado de las } \\
\text { plantas. } \\
\text { Plantar una semilla en } \\
\text { la tierra. } \\
\text { Darle una regadera } \\
\text { para que riegue las } \\
\text { plantas. }\end{array}$ & Jardín o el área de plantas. \\
\hline
\end{tabular}

Fuente: Elaboración propia.

\section{Tarjetero con actividades}

Elaborar tarjetas en donde se describan las actividades que pueden realizarse con los bebés. Se recomienda realizar tarjetas para cada etapa del desarrollo del bebé. Como podemos ver en la figura 2, presento una idea de tarjeta con componentes didácticos a incluir: el nombre de la actividad; la etapa del bebé en semanas y / o meses; el propósito para el desarrollo del bebé; describir la metodología de la actividad paso a paso; el lugar para realizar la actividad; los recursos para lograr la actividad; el rol del profesional y la duración de la actividad (adaptada a la edad del bebé). En la duración debe contemplarse tanto el tiempo de la planeación, de la realización misma de la actividad, así como el tiempo que se requerirá para escribir en el expediente de cada bebé lo que se observó durante la actividad.

Figura 2. Tarjeta con actividades

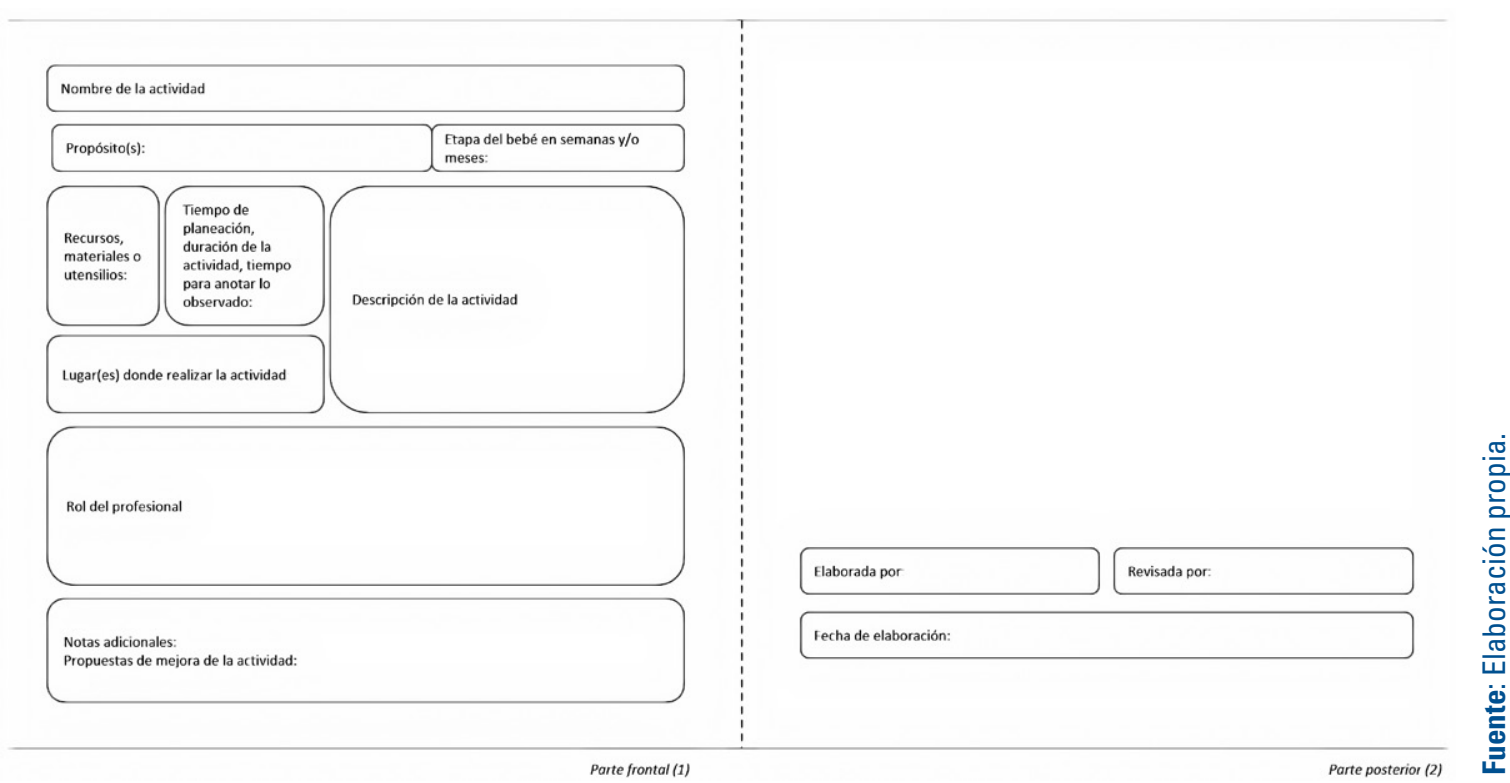




\section{El rol del profesional}

Reflexionar sobre su labor, no solo como cuidadores en ausencia de los padres, sino como guías activos en el proceso de aprendizaje de cada bebé. Reflexionar en conjunto sobre el impacto emocional y afectivo de su trabajo, más allá de procurar cuidados y satisfacer necesidades de los bebés. Los bebés son los actores centrales de su propio aprendizaje y son ellos quienes dan vida al proyecto pedagógico, mediante la guía de los profesionales.

\section{Listado de conductas observables}

Llevar un control de los avances o retrasos en el desarrollo de cada bebé con el fin de alentarlos y ayudarlos en su propio proceso. Este control puede incluirse en el dosier de cada bebé.

\section{Máximas de enseñanza-aprendizaje}

Este trabajo podrá realizarse entre los directores y los trabajadores de la guardería. El propósito es redactar enunciados que guíen el rol del personal y brinden claridad a los padres sobre la forma de educación que se ofrece. Ejemplos:

- Aprender a compartir.

- Aprender a respetar a los demás.

- Aprender a reír sanamente.

- Aprender a confiar en los otros.

- Aprender a recibir ayuda.

- Aprender a vestirse.

- Aprender a comer.

- Aprender a cuidar a plantas y animales.

- Aprender reglas de cortesía.

- Aprender canciones.

- Aprender otro idioma.

- Aprender a no renunciar y volver a intentarlo.

- Aprender a respetar el juego de los otros.

- Aprender dimensiones de las cosas y formas geométricas.

- Aprender a rodar, gatear, caminar.

- Aprender a jugar solo y con otros.

- Aprender a vivir de manera individual.

Como hemos analizado, los bebés son personas en desarrollo que aprenden constantemente y el tiempo que pasen en las guarderías debe ser de calidad. Se sugiere sistematizar algunos de los momentos en los que aprenden, para encuadrar la labor de guías de los profesionales de la primera infancia. 
Si bien es cierto que no podemos estructurar el aprendizaje vicario de los bebés -ya que cada uno es único y diferente-, sí podemos estructurar algunas las actividades dirigidas por los profesionales para despertar el desarrollo de los bebés / niños.

Es fundamental que los profesionales de la primera infancia estén conscientes de las acciones, palabras, la posición de su cuerpo, los movimientos con manos, gestos, miradas, que realizan frente a los bebés, ya que son sus modelos de vida, en ausencia de sus padres. Seamos reflexivos con el ejemplo que les ofrecemos a los bebés.

\section{APÉNDICE}

Francia y Hungría son los países de la Unión Europea que iniciaron la educación obligatoria a más temprana edad: a los tres años. Para facilitar la lectura de la figura A1, podemos observar las edades en la primera fila, sombreada en color gris (de tres a 19 años), y en la primera columna, la abreviatura de los países y / o regiones de países.

Figura A1. Educación obligatoria en los países de la Unión Europea-2020/21

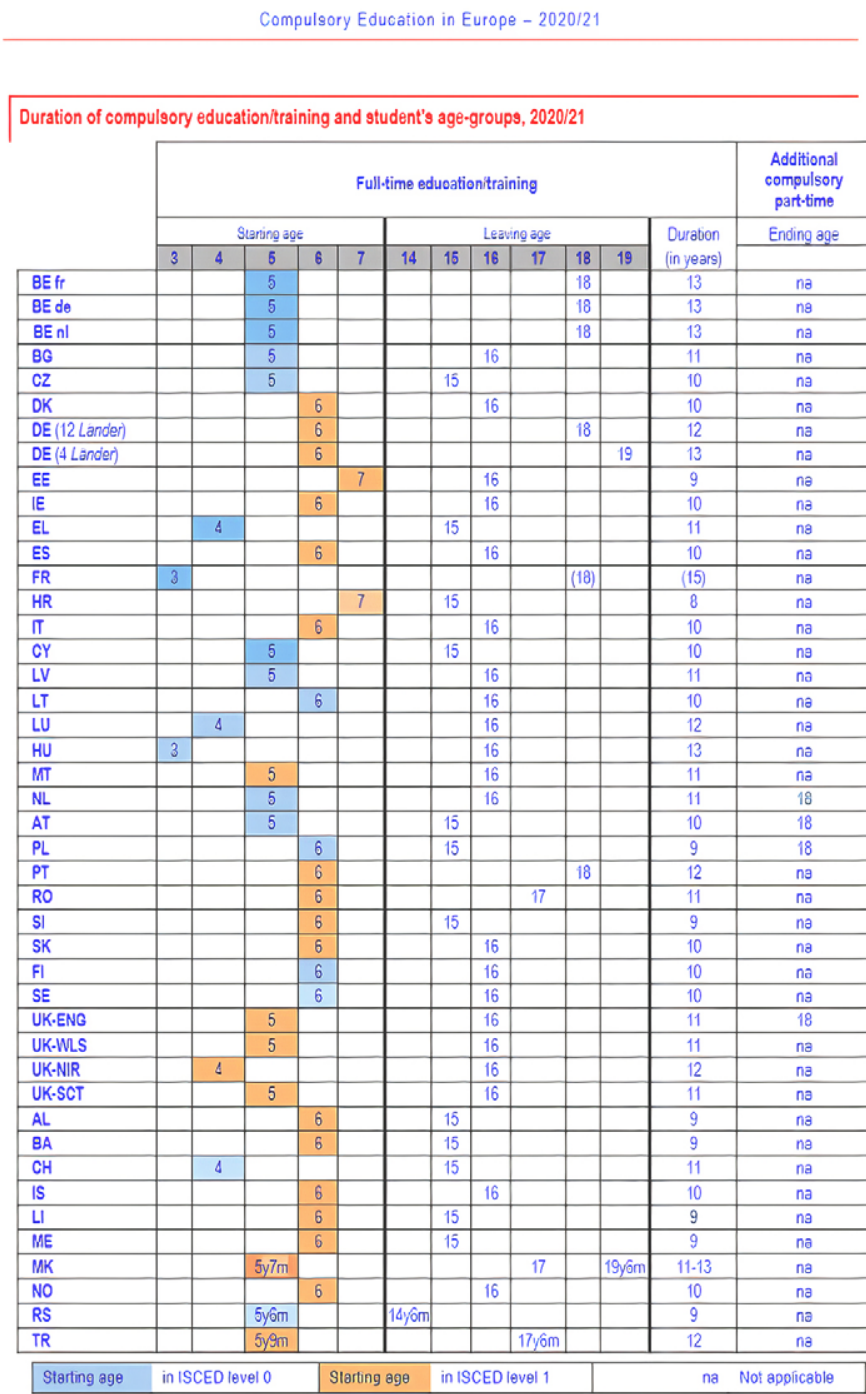

Nota: Tomado de Compulsory education in Europe-2020/21 (p.4), por European Commission/ EACEA/Eurydice, 2020, EurydiceFacts and Figures, Luxemburg: Publications Office of the European Union. 
A modo de resumen señalamos que en la tabla A1, podemos ver la edad de inicio de la educación obligatoria y los países con la abreviatura utilizada en la Figura A1.

Tabla A1. Edad de inicio de la educación obligatoria

\begin{tabular}{|c|c|}
\hline $\begin{array}{l}\text { Edad de } \\
\text { inicio }\end{array}$ & País \\
\hline 3 años. & Francia (FR) y Hungría (HU). \\
\hline 4 años. & Grecia (EL), Luxemburgo (LU), Irlanda del Norte (UK-NIR) y Suiza (CH). \\
\hline 5 años. & $\begin{array}{l}\text { Bélgica (BE), Bulgaria (BG), República Checa (CZ), Chipre (CY), Letonia (LV), Malta } \\
\text { (MT), Países Bajos (NL), Austria (AT), Inglaterra (UK-ENG), Gales (UK-WLS) y } \\
\text { Escocia (UK-SCT). }\end{array}$ \\
\hline $\begin{array}{l}\text { Entre los } \\
5 \text { y } 6 \text { años. }\end{array}$ & Macedonia del Norte (MK), Serbia (RS) y Turquía (TR). \\
\hline 6 años. & $\begin{array}{l}\text { Dinamarca (DK), Alemania (DE), Irlanda (IE), España (ES), Italia (IT), Lituania } \\
\text { (LT), Polonia (PL), Portugal (PT), Rumania (RO), Eslovenia (SI), Eslovaquia (SK), } \\
\text { Finlandia (FI), Suecia (SE), Albania (AL), Bosnia y Herzegovina (BA), Islandia (IS), } \\
\text { Liechtenstein (LI), Montenegro (ME) y Noruega (NO). }\end{array}$ \\
\hline 7 años. & Estonia (EE) y Croacia (HR). \\
\hline
\end{tabular}

Fuente: Elaboración propia.

\section{REFERENCIAS}

VV.AA. (2003). Diccionario de las Ciencias de la Educación. México: Editorial Santillana.

European Commission/EACEA/Eurydice (2020). Compulsory education in Europe-2020/21. Eurydice-Facts and Figures. Luxemburg: Publications Office of the European Union. https: / / op.europa.eu/en/publication-detail/-/ publication/5a630699-1f17-11eb-b57e01aa75ed71a1/language-en/format-PDF/source-search

European Commission/EACEA / Eurydice. (2020). The structure of the European Education Systems 2020/21. Schematic Diagrams. Eurydice-Facts and Figures. Luxemburg: Publications Office of the European Union. https://op.europa.eu/en/publication-detail/-/publication/ f4784939-1f15-11eb-b57e-01aa75ed71a1/language-en/format-PDF/source-search

Jones, E.J.H. \& Herbert, J.S. (2006). Exploring memory in infancy: Deferred imitation and the development of declarative memory. University of Sheffield, UK: Infant and Child Development.

Le P'tit Club (2021). https:/ / www.ptitclub.fr/?page id=9785

Légifrance. Journal Officiel (2000). Décret $n^{\circ} 2000-762$ du 1er août 2000 relatif aux établissements et services d'accueil des enfants de moins de six ans et modifiant le code de la santé publique). République française: Décrets en Conseil d'État (deuxième partie). https://www. legifrance.gouv.fr/jorf/id/JORFTEXT000000218271/ 
Meltzoff, A. (2019). Au commencement était d'imitation [Al principio era la imitación]. En B. Cyrulnik. Boris Cyrulnik et la Petite Enfance [Boris Cyrulnik y la Primera Infancia], 110124. République française: Editions Philippe Duval.

Michaud, L. (2019). Pour les bébés, des espaces de plaisir! [Para los bebés, jespacios de placer!] En B. Cyrulnik. Boris Cyrulnik et la Petite Enfance [Boris Cyrulnik y la Primera Infancia], 518-526. République française: Editions Philippe Duval.

Ministère de l'éducation nationale, de la jeunesse et des sports (2020). La loi pour une école de la confiance. https: / / www.education.gouv.fr/la-loi-pour-une-ecole-de-la-confiance-5474

Ministère des solidarités et de la santé. (2020). Accueil du jeune enfant. Charte nationale pour l'accueil du jeune enfant [Atención a la primera infancia. Carta Nacional para el cuidado de los niños pequeños]. https://solidarites-sante.gouv.fr/IMG/pdf/accueil jeune enfant cadre national.pdf

Ministère de l'Europe et des affaires étrangères (2017). La acción de Francia a favor de los derechos del niño. Francia Diplomacia. Política exterior. Derechos de los niños. https://www. diplomatie.gouv.fr/es/

OCDE (2017). Mejorar la educación y la atención de la primera infancia para ayudar a más niños a lograr un buen arranque en la vida y a fomentar la movilidad social, dice la OCDE. https:// www.oecd.org/centrodemexico/medios/mejorar-la-educacion-y-la-atencion-de-laprimera-infancia-para-ayudar-a-mas-nios-a-lograr-un-buen-arranque-en-la-vida-y-afomentar-la-movilidad-social-dice-la-ocde.htm

OCDE (2017). Starting Strong Key OECD Indicators on Early Childhood Education and Care. https:/ / www.oecd.org/publications/starting-strong-2017-9789264276116-en.htm

Rayna, S. (2003). Regard sur les apprentissages des tout-petits. Comment les enfants apprennentils [Una mirada al aprendizaje de los niños pequeños. ¿Cómo aprenden los niños?]. République française: Enfances \& Psy 2003/ 4 (n²4), 30-41. https: / /www.cairn-int.info/

Rochegude, A.S. (2019). Libre exploration éducative: un mouvement de pensée [La libre exploración educativa: un movimiento de pensamiento]. En B. Cyrulnik. Boris Cyrulnik et la Petite Enfance [Boris Cyrulnik y la Primera Infancia], 496-505. République française: Editions Philippe Duval.

Shaffer, David R. (2002). Teorías clásicas del desarrollo social y de la personalidad. Desarrollo social y de la personalidad, 39-73. España: Editorial Paraninfo.

UNESCO. (2020). La atención y educación de la primera infancia. Organización de las Naciones Unidas para la Educación, la Ciencia y la Cultura. https://es.unesco.org/themes/ atencion-educacion-primera-infancia

UNESCO. (2016). Education 2030: Incheon Declaration and Framework for Action for the implementation of Sustainable Development Goal 4: Ensure inclusive and equitable quality education and promote lifelong learning. United Nations, Educational, Scientific and Cultural Organization. Digital Library. http://uis.unesco.org/sites/default/files/documents/ education-2030-incheon-framework-for-action-implementation-of-sdg4-2016-en 2.pdf

UNESCO (1999). Cuidado y desarrollo de la primera infancia. El desarrollo del niño en la primera infancia: echar los cimientos del aprendizaje. Informe temático. Educación para Todos-hacerla realidad. UNESCO-Sector de Educación. https://unesdoc.unesco.org/ark:/48223/ pf0000116350 spa 